\title{
Research on Tacit Knowledge Management Strategies in Library Information Consulting Service
}

\author{
Shen $\mathrm{Si}$ \\ Library \\ Xi'an University of Science \& Technology (XUST) \\ Xi'an, China \\ E-mail address: shensi72@126.com
}

\author{
Yang Yujia \\ Faculty of Social \\ Science University of Macau \\ Macau, China \\ E-mail address: sb42250@umac.mo
}

\begin{abstract}
In order to realize the tacit knowledge management in library information consulting service, starting from the concept of tacit knowledge management and the types and contents of tacit knowledge in libraries, the necessity for tacit knowledge management in the library information advisory services was introduced. The strategies on the tacit knowledge management for the advisory services were suggested, that is to strengthen the organizational building and technical support, emphasize on the management of consultation process, and establish an effective tacit knowledge-sharing incentive system. The tacit knowledge management strategies and activities should be integrated with the behaviors of librarians, so that the work efficiency of advisory librarians was maximized.
\end{abstract}

Keywords-tacit knowledge; knowledge management; consulting service; library

\section{INTRODUCTION}

Bassi(1997) believes that knowledge management refers to the process of creating, acquiring and using knowledge in order to enhance organizational performance [1]. Quitas P (1997) considers knowledge management as a continuous process of managing various knowledge to meet current and future emerging needs, to identify and explore existed and acquired knowledge assets and develop new opportunities[2]. American Productivity and Quality Center (APQC) believes that knowledge management should be the organization of a conscious strategy that ensures that the most needed knowledge is transmitted to the people who need it most at the most necessary time. The famous scholar Professor Ma Jiapei $(1998,1999)$ argues that "knowledge management is a new period of the information management development, which is different from the other periods, need to link information with information, information and activities, information and people, in the interaction process of interpersonal communication, through the sharing of information and knowledge (including explicit knowledge and tacit knowledge), using the wisdom of groups to innovate, in order to win the competitive advantage[3].

In summary, knowledge management refers to the systematic management process of knowledge acquisition, storage, learning, sharing and innovation of an organization. Therefore, knowledge content management is not only the collection, processing, organization and dissemination of explicit knowledge, but more importantly is also to creatively make use of knowledge, promote the transfer of knowledge, mine tacit knowledge, and realize all knowledge innovation and sharing.

In recent years, the research on library knowledge management has been fruitful[4-6], However, the research on how to realize the tacit knowledge management is still rare in the information consulting service, which is the most knowledgeable, technical and empirical business in the library. Therefore, in the information consultation, the mining, organization, processing and sharing of tacit knowledge has become the most important task of library knowledge management.

\section{THE TYPES AND CONTENTS OF TACIT KNOWLEDGE IN LIBRARIES}

Tacit knowledge is a form of knowledge that is not clearly expressed in systematic or coded language. It is a subjective feeling of long-term interaction between people who are subjects and objects in various social activities. It is the judgment, perception and cognition of people's external affairs, as well as the imitation of other people's actions. Such judgment, perception, cognition, and imitation come from practice and experience. Tacit knowledge mainly contains 5 factors, such as cognition, emotion, belief, experience and skill. According to the subject that the tacit knowledge depends on and shows, it can be divided into two categories: personal tacit knowledge and collective tacit knowledge [7].

As for the library, personal tacit knowledge mainly includes: Librarians' ability on scientific research, ability to analyze and solve problems in the process of knowledge mining and knowledge reorganization, ability to accept new things and find and solve the question, work experience and judgment, occupation morality and librarians on career values and position, personal knowledge and technology, information retrieval ability and insight and foresight of the librarian's decision making. Collective tacit knowledge mainly includes: the library's long established working methods; the common experience of librarians' dealing with problems at work; the mechanism of knowledge communications among librarians, 
and between librarians and readers; library's ability to cope with emergency events and coordination in internal and external environment; the overall level of library services and reputation; affinity and cohesion within the library and the common work philosophy, moral belief and spiritual outlook embodied in the thoughts and actions of all librarians. Generally speaking, in the library's unique organizational structure, business processes, operating mechanisms and organizational culture, there is a wealth of intangible implicit knowledge, personal tacit knowledge is the basis of collective tacit knowledge. The consensus and tacit understanding formed by mutual exchanges and cooperation of librarians throughout the library for a long time, often with an invisible inner strength affects all aspects of the organization, which become foundation of collective tacit knowledge growth [4].

\section{THE NECESSITY OF TACIT KNOWLEDGE MANAGEMENT IN INFORMATION CONSULTING SERVICE}

\section{A. The connotation of information consulting service}

Library information consultation is a knowledge intensive intelligent service work. Based on the resources of specialized information, knowledge, skills and experience, it provides users with the knowledge product and knowledge service, uses various methods to help users solve the information access barriers, or provide them with necessary literature, or provide suggestions and solutions to a problem. It is one of the most important services in library reader service, which reflects academic, intellectual, social and comprehensive characteristics of librarians. The essence of information consulting service is the transfer of knowledge, intelligence and ideas. For a long time, information consulting has been engaged in knowledge development, knowledge organization and knowledge management, and also engaged in consulting management related to knowledge management activities. Therefore, information consulting and knowledge management are not only closely related, but also bring new ideas, new contents and new development for each other[6].

The rise of knowledge economy and knowledge management is de facto conducive to improving the social status of librarians and consulting services, which means more information needs makes people realize the importance of information and knowledge. On the other hand, higher expectations for advisory services force librarians to continuously improve service levels and service quality in information consultancy[7]. Knowledge management has been applied in the information consulting work of American libraries. They suppose that knowledge should be regarded as a kind of property and attention is paid to the acquisition of tacit knowledge, to the knowledge management process of work process, and to the knowledge management strategy and its connection with behavior.

\section{B. The necessity of tacit knowledge management in information consulting work}

- Information consultation needs sharing of tacit knowledge. Because the content of information consultation is broad, inter-cross, diversity, finality and complexity, it is also a form of intelligence that combines theory with practice. The role of the librarian is not merely the information searcher and transmitter, but also the researcher and director of the subject[7]. Therefore, the librarian must have relevant professional knowledge, information service experience and foreign language translation ability; however, there is still a lack of high-level and complex professionals in library information consultation. It is necessary to strengthen self-training and introduction so as to guarantee the basic intellectual requirement of reference service. Secondly, the consulting subject is the most active and decisive factor in the whole consulting system. It is far from enough to rely only on the library consultant to deal with all kinds of consulting issues. Modern information consulting services involve all kinds of intellectual resources in Natural Sciences and Social Sciences, and need all kinds of expert[8], need to cooperate with other consulting departments outside of the campus, other academic organizations or experts outside the library. An intelligent human resource sharing system consisting of all kinds of experts should be established to achieve a broader intelligence reserve to meet the needs of various consulting services, and to complete the consultation tasks in a quality and quantity manner. We can also use the established data warehouse, tacit knowledge units, various consulting services, and experience and intelligence resources. Through the sharing of tacit knowledge, library staff can exchange and discuss the consulting experience and skills of tacit knowledge between the library and internal, and boost the service innovation ability of such knowledge providers In the process of sharing their knowledge with other people, a knowledge provider can correct the mistakes or deficiencies in the existing knowledge. Through communication, the recipient may get some enlightenment, and then form new tacit knowledge; at the same time, the recipient obtains the practical knowledge of others in the process of consultation and internalizes them into their own knowledge. Through this process, the recipient, to some extent, also accumulated empirical knowledge of consulting service, and provided the theoretical and practical basis for his innovative consultancy service in the future [9].

- Information consultation needs the preservation of tacit knowledge. Because tacit knowledge is the judgment and reflection of external things and the experience and knowledge of their own practice. Therefore, a rich knowledge stock is needed for information consulting service, especially the tacit knowledge of the consulting team. The amount of organizational knowledge stock depends on the degree of employee knowledge sharing, transfer and preservation. If the tacit knowledge gained in the consultation process is shared with other employees, and retained by other consultants, the knowledge of the organization can grow exponentially. On the other hand, by retaining the tacit knowledge of the librarians, they can avoid taking away their tacit knowledge due to the departure of librarians, and also increase the knowledge of the consulting team to a certain extent. 
- Information consultation needs the externalization of tacit knowledge. In the process of consultation, we should reference and analyze the explicit knowledge of existing cases, and try to share and transfer the tacit knowledge of experienced people as much as possible. Using the discussion platform of knowledge management, personal homepage, and knowledge management systems, the librarian can turn their difficult experience into a shared explicit knowledge by the mean of metaphor, analogy, imagination, language stories, visualization tools, models, charts, etc. Because consulting is an experience-oriented industry, the more experience we use in the service innovation process, the less risk of failure will occur.

\section{THE STRATEGY OF TACIT KNOWLEDGE MANAGEMENT IN INFORMATION CONSULTING SERVICE}

\section{A. Organization construction}

The purpose of organizational construction is to enable librarians to have a sense of belonging and a sense of ownership. First of all, it is necessary to establish an organizational mechanism based on consulting librarians. This organizational mechanism requires flattening the organizational structure, and gives everybody a full scope to his or her talent. Because tacit knowledge is the foundation for the survival, development and self-realization of information consulting librarians.

Secondly, we should establish a learning organization based on information and knowledge, which can implement the goal management, and members' self-learning, development and self-control. Within the library, a variety of academic groups can be formed, which can be divided by discipline or technical category, so that individual tacit knowledge can be shared through group meetings. Establishing study groups and classes to let librarians realize the responsibility and obligation of their trying to achieve the common desire can also hire experts to guide the learning organization, to exchange of knowledge among librarians or between librarians and the external, enabling them to achieve self-transcendence by team learning. For example, the University of Maryland Library established learning organization based on team (Team-Based), and on its website, creating a learning organization space, the organization development department, member of learning and development department, and planning department in the space are set up to let the library staff continue to learn and share knowledge, thus improve the quality of service [10].

\section{B. Technical support}

Technical support is an important way to increase the tacit knowledge sharing among librarians. Library allows the advisory staff to communicate by e-mail, BBS, chat rooms and other network mode at any time and place to facilitate staff exchange experience, and learn lessons. The library can also organize librarians to collate and mine tacit knowledge, search for the knowledge that improves their consulting ability or creative ability, explicit this knowledge and put them into the knowledge base for all employees to learn and use.

\section{Pay attention to the management of information consulting process}

The following information consultation processes are generally used: 1 . Receive the reader's question; 2 . Analyze the question and then determine what information needs; 3 . discuss on the question; 4. Identification and selection of specific reference tool that can provide answers; 5 . Select reference sources that can provide answers 6. Convey selected information to the reader; 7 . If the reader satisfied with the answer, this process ended, if he or she is not satisfied with the answer, the librarian need to re-negotiate and repeat the above $2 \sim 6$ steps[11]. So far, the library has not changed the basic consulting process and found that the process is not enough to improve work efficiency. In order to identify the best strategy and promote lifelong-learning, librarians need to make the integration of tacit knowledge management and consultation process, to record or report and analyze the reason of failure, to record the interaction of consulting activities in detail, and to analyze and provide experts to evaluate the success of the consultation after every consultation work has been completed [12]. If there was no additional reporting process and failure analysis steps, consultants wouldn't have sufficient grounds and standards to improve the work behavior and work efficiency.

\section{Establish an effective incentive system for tacit knowledge management}

The tacit knowledge sharing incentive system is to give all employees of sharing tacit knowledge certain spiritual and material rewards, reflect the fairness of the consulting company to employees, increase staff's sense of achievement, and enhance the sense of belonging. On one hand, the sense of achievement and recognized satisfaction can be received by communicating with leaders, colleagues, expressing a unique views, opinions and suggestions; on the other hand, only when there is a sense of trust between leadership and colleagues, do consulting librarians have a sense of belonging, the master spirit, they are willing to do the best for the library, and mining their greatest potential - tacit knowledge to gain recognition and fulfillment. In order to achieve the above objectives, the library must set up a complete, effective, stable and personalized incentive system. On one hand the completeness of the incentive system embodied in the incentive object must contain all the staff; on the other hand the existing incentive must be comprehensive; the effectiveness of knowledge sharing can stimulate the enthusiasm of each Librarian in the incentive system; the reward standard is greatly achievable; the stability is reflected by the long-term effectiveness of the rewards and punishments of the incentive system, which does not change with the mood of leadership; and the personalization is reflected by the "tailored" incentive system for the different reference librarian's characters with the different degree of tacit knowledge.

\section{CONCLUSIONS}

Information consulting service is one of the important ways for library services, which represents the development direction of the library work under the Internet environment. In addition, the use of relevant theories and methods of tacit knowledge 
management are very important to guide the work of information consultation.

Under these circumstances, information consultation librarians must change the role from "manager of the literature" to "the manager of a group of memory", change the work from traditional search, selection, organization and management of information to creation and management of knowledge, and also transfer their role from "the manager which organize the information for others" to "the real knowledge workers which regard knowledge as a major aspect of their work and require a high level of technique skill”[13] .

Therefore, in order to realize the tacit knowledge management in information service, we must strengthen organization construction and technical support, pay attention to the information management process, and establish an effective incentive system of tacit knowledge management. And the activities and strategies of tacit knowledge management should be integrated with librarians behavior to maximize the consulting librarians ' work efficiency.

\section{ACKNOWLEDGMENTS}

Thanks for financial support from Special Fund of Education Department of Shaanxi Province (13JK0445), Ideological and political education research project of XUST (17SZ106) and Mr MENG Chang-chun's help.

\section{REFERENCES}

[1] Bassi. Harnessing the power of intellectual capital[J]. Training \& Development, 1997, 51 (12): 25-30

[2] Quitas P, Jones G, Jones G. Knowledge Management: A Strategic Agenda[J]. Long Range Planning. 1997,30,(3):385-391

[3] Ma Jiapei. Information society and network [M]. Beijing: Science and Technology Literature Press, 1999.(In Chinese)

[4] Dong Yuping, Wu Ting. Case study of tacit knowledge management in Library [J]. Sci-Tech Information Development \& Economy, 2015, (01): 65-67.(In Chinese)

[5] Shen Si, Wang Xiaowen, Cui Xu. Mobile information service quality evaluation for College Library Based on planned behavior theory [J]. Journal of Modern Information, 2016, (02): 70-73+85.(In Chinese)

[6] Ma Haiqun. Modern decision-making and consultation[M].Harbin: Heilongjiang people's Publishing House.2002: 96 - 103(In Chinese).

[7] Cheng Shi. Study on knowledge field in Library Tacit Knowledge Management [J]. Research on library science , 2014, (05): 32-36.(In Chinese)

[8] Yan Beini, Li Yujia. Research on tacit knowledge transfer of Library Based on cognitive structure[J]. Information Studies: Theory \& Application, 2015, (10): 89-94.(In Chinese)

[9] Jane T. Bradford. Barbara Costello. Reference service in the digital age: an analysis of sources used to answer reference questions[J]. The Journal of Academic Librarianship.2005,31(3):263 - 272

[10] Wang Peilin. The Enlightenment of maker space on tacit knowledge transfer in public libraries [J]. library, 2017, (02): 33-38. (In Chinese)

[11] Wang Xiaowen, Shen Si. Review and Enlightenment of data literacy education of foreign researchers [J]. Library and information service, 2017, (03): 102-106.(In Chinese)

[12] MH Harun. Integrating e-Learning into the workplace[J]. Internet and Higher Education, 2002 (4): 301-310.

[13] Wagner, Cynthia G. The Rise of the Knowledge Manager[J] . Futurists, 2002, 36 (2): 14-15 